\title{
Accuracy of the Brazilian version of the Functional Activities Questionnaire in the screening of dementia
}

Acurácia da versão brasileira do Functional Activities Questionnaire no rastreio de demência Precisión de la versión brasileńa del Functional Activities Questionnaire en el seguimiento de la demencia

Rafael Tavares Jomar*(D); Roberto Alves Lourenço**(D); Claudia de Souza Lopes***(D)

\section{Abstract}

Background: Instruments for measuring functional disability of the elderly, such as the Functional Activities Questionnaire, can be used for the detection and prediction of dementia.

Objective: To evaluate the accuracy of the Brazilian version of the Functional Activities Questionnaire (FAQ-BR) in dementia screening.

Methodology: Cross-sectional study with 265 elderly and their respective informants. The performance of the FAQ-BR was compared to the clinical diagnosis of dementia and their score compared to screening instruments for cognitive decline/dementia. The receiver operating curve (ROC curve) was used to determine the sensitivity and specificity of the best cutoff.

Results: The area under the ROC curve indicated an accuracy of $79.7 \%$ with cutoff point $\geq 14$, which showed the highest sensitivity $(80.0 \%)$ and specificity $(72.0 \%)$. The FAQ-BR score showed high correlations with the scores of the cognitive decline/dementia screening instruments.

Conclusion: The area under the ROC curve, sensitivity and specificity of the FAQ-BR were found to be inappropriate, and it was not possible to recommend its use in dementia screening.

Keywords: evaluation of research programs and tools; activities of daily living; dementia; health of the elderly; validation studies

\section{Resumo}

Enquadramento: Instrumentos de aferição da capacidade funcional do idoso, como o Functional Activities Questionnaire, podem ser utilizados para a deteçáo e predição de demência.

Objetivo: Avaliar a acurácia da versão brasileira do Functional Activities Questionnaire (FAQ-BR) no rastreio de demência.

Metodologia: Estudo transversal realizado com 265 idosos e seus respetivos informantes. O desempenho do FAQ-BR foi comparado ao diagnóstico clínico de demência e a sua pontuação comparada à de instrumentos de rastreio de declínio cognitivo/demência. A curva receiver operating curve (ROC) foi utilizada para determinar a sensibilidade $\mathrm{e}$ a especificidade do melhor ponto de corte.

Resultados: A área sob a curva ROC indicou acurácia de $79,7 \%$ com ponto de corte $\geq 14$, que mostrou as máximas sensibilidade $(80,0 \%)$ e especificidade $(72,0 \%)$. A pontuação do FAQ-BR apresentou correlaçóes altas com as pontuaçóes dos instrumentos de rastreio de declínio cognitivo/demência.

Conclusáo: A área sob a curva ROC, a sensibilidade e a especificidade do FAQ-BR mostraram-se inapropriadas, não permitindo recomendar o seu uso no rastreio de demência.

Palavras-chave: avaliação de programas e instrumentos de pesquisa; atividades cotidianas; demência; saúde do idoso; estudos de validaçáo

*Ph.D., RN, José Alencar Gomes da Silva National Cancer Institute, 20230-130, Rio de Janeiro, Brazil [rafaeljomar@yahoo.com.br]. (1) https://orcid.org/0000-0002-4101-7138. Contribution to the article: bibliographical research; methodology planning; treatment and data analysis; article writing. Address for correspondence: Praça Cruz Vermelha, 23, 20230-130, Centro, Rio de Janeiro, Brasil.

**Ph.D., Doctor, Rio de Janeiro State University, 20950-000, Rio de Janeiro, Brazil [roberto.lourenco@globo.com]. (0) https://orcid.org/0000-0003-0838-1285. Contribution to the article: study design; methodology planning; article revision.

****Ph.D., Doctor, Rio de Janeiro State University, 20550-900 , Rio de Janeiro, Brazil [cslopesims@gmail.com]. (D) https://orcid.org/0000-0002-0401-689X. Contribution to the article: methodology planning; article revision.

\section{Resumen}

Marco contextual: Los instrumentos para evaluar la capacidad funcional de los ancianos, como el Functional Activities Questionnaire, pueden utilizarse para detener y predecir la demencia.

Objetivo: Evaluar la precisión de la versión brasileña del Functional Activities Questionnaire (FAQ-BR) en el seguimiento de la demencia.

Metodología: Estudio transversal realizado con 265 ancianos y sus respectivos informantes. El rendimiento del FAQ-BR se comparó con el diagnóstico clínico de demencia y su puntuación con la de los instrumentos de seguimiento del deterioro cognitivo/demencia. La curva de característica operativa del receptor (ROC, en inglés) se utilizó para determinar la sensibilidad y especificidad del mejor punto de corte.

Resultados: El área bajo la curva ROC indicó una precisión del $79,7 \%$ con punto de corte $\geq 14$, que mostró sensibilidad máxima $(80,0 \%)$ y especificidad $(72,0 \%)$. La puntuación del FAQ-BR mostró altas correlaciones con las puntuaciones de los instrumentos de seguimiento del deterioro cognitivo/demencia.

Conclusión: En el área bajo la curva ROC, la sensibilidad y la especificidad del FAQ-BR resultaron ser inapropiadas, por lo que no se pudo recomendar su uso en el seguimiento de la demencia.

Palabras clave: evaluación de programas e instrumentos de investigación; actividades cotidianas; demencia; salud del anciano; estudios de validación 


\section{Introduction}

The Functional Activities Questionnaire (FAQ) is a scale aimed at determining the functional ability of the elderly, based on evaluating the level of dependency in performing 10 activities that are instrumental in daily life. These include managing finances; handling documents; shopping; hobbies; preparing coffee/tea; preparing full meals; being involved in current affairs; following and understanding soap operas or newspapers; remembering commitments, household tasks or medications; and using transportation to leave the neighborhood (Pfeffer, Kurosaki, Harrah Jr, Chance, \& Filos, 1982). The FAQ is the tool for assessing the functional ability of the elderly based on the informant's report that is most used in research studies (Paixão Junior \& Reichenheim, 2005), and the preference for this tool is likely related to its short implementation period (Sanchez, Correa, \& Lourenço, 2011). Although it was presented to the scientific community in 1982, few studies have examined its performance, particularly evaluations of the validity of criteria predicting dementia (Cruz-Orduña et al., 2012; Juva et al., 1997; Pfeffer et al., 1982).

Although some tools have been developed to determine the functional ability of the elderly, the clinical diagnosis of dementia is still considered the gold standard. Characterized by the persistent cognitive decline, where primarily memory is compromised, dementia interferes significantly with the functional ability of the elderly, since its progression compromises the fulfillment of daily activities, giving rise to disabilities and functional dependency (Fagundes, Pereira, Bueno, \& Assis, 2017; World Health Organization [WHO], 2017). In this way, tools that measure the functional ability of the elderly may be used to detect and predict dementia (Barberger-Gateau, Fabrigoule, Helmer, Rouch, \& Dartigues, 1999; Juva et al., 1997), since the functional status interacts in such a way with the cognitive dimension that any change in this dimension involves some functional impairment (Fagundes et al., 2017; Paixão Junior \& Reichenheim, 2005; WHO, 2017). Since knowing the diagnostic properties of the FAQ's Brazilian version (FAQ-BR) is essential to apply it to epidemiological studies - in the case of elderly absence, their inability to respond, or if there is a concern that their self-reporting is not trustworthy - this study aimed to evaluate the accuracy of FAQ-BR in screening for dementia, based on the informant's report on the elderly.

\section{Background}

The FAQ was developed in English by a group of researchers from the Department of Neurology at the University of California, for use with the spouse, family member or close friend of the elderly, that is, its results are based on the report of an informant who knows the routine and performance of the elderly in daily activities (Pfeffer et al., 1982). The testimonials of an informant are trustworthy since they can adequately describe, in retrospect, the elderly person's behavior, since they know the subject's routine, functional performance status, and dependency-related limitations. It is worth noting that, in the event of cognitive decline, the elderly's self-report may become untrustworthy and the informant may, invariably, disagree with the level of performance in daily activities claimed by the elderly (Hendry, Quinn, Evans, \& Stott, 2015).

The study that describes the development and validity of the FAQ (Pfeffer et al., 1982) reported high levels of interexaminer reliability, ranging from 0.80 to 0.97 and item-total correlation $(r=0.80)$. Also, it indicated appropriate validity of criteria predicting dementia, diagnosed by a neurologist, when the informant described the elderly's dependency in more than two instrumental daily activities (sensitivity: 85\%; specificity: $81 \%$ ).

Cruz-Orduña et al. (2012) examined the performance of the FAQ in screening dementia among 160 informants of elderly who were patients of primary healthcare services in Spain. The results indicated as appropriate the sensitivity (87\%) and the specificity (82\%), as well as the area under the receiver operating curve (ROC) being equal to 0.91 . In evaluating the performance of different measurements of functional ability of elderly for detecting dementia, a Finnish study, based on reports by 795 informants, reported appropriate performance by the FAQ: sensitivity at $94 \%$, specificity at $84 \%$ and the area under the ROC curve equal to 0.96 (Juva et al., 1997). 
In order to present a FAQ version to be used in Brazil, the first stages for its transcultural adaptation were undertaken, namely: conceptual equivalences, items, semantics, operation, and evaluation of internal consistency and reliability. The FAQ-BR presented internal consistency of 0.95 and an intraclass correlation coefficient of 0.97 when applied to a non-probabilistic sample of 65 informants for the elderly (Sanchez et al., 2011). Recent studies (Jomar, Lourenço, \& Lopes, 2017; Jomar, Lourenço, $\&$ Lopes, 2018) presented evidence that this version shows appropriate construct validity, bidimensional structure and internal consistency for gauging the functional ability of the elderly based on an informant's report. In evaluating its dimensional structure, in particular, the 10 items were able to capture different areas of functional ability of the elderly (Jomar et al., 2018), which are: Autonomy/Independence (Sposito, Neri, \& Yassuda, 2016) and Memory/ Cognition (Fagundes et al., 2017; Paixão Junior $\&$ Reichenheim, 2005).

\section{Methodology}

A cross-sectional study was developed between 2009 and 2010 on the baseline of a cohort of non-institutionalized elderly: the Frailty in Brazilian Elderly Study - Rio de Janeiro Section (FIBRA-RJ). The eligibility criteria were: age 65 or older; having been a patient of a health operator (target population) for at least 12 months; and, residing in a neighborhood in the northern part of the city of Rio de Janeiro. Other methodology aspects of the FIBRA-RJ were presented in detail in another publication (Lourenço et al., 2015).

The FIBRA-RJ was organized in two stages: screening for cognitive compromise in the baseline of the cohort $(N=847)$; diagnostic evaluation of dementia in the elderly participants in the first stage who showed cognitive decline and functional disability $(n=221)$, as well as an evaluation of a sample of elderly without cognitive compromise $(n=44$; Lourenço et al., 2015). The non-probabilistic sample in this study consisted, therefore, of 265 elderly participating in the second stage of the FIBRA-RJ and their corresponding informants. The existence of cognitive compromise was established in the baseline of the FIBRA-RJ using the cut-off of $\leq 27$ in the Mini-Mental State Examination (MMSE; Brucki, Nitrini, Caramelli, Bertolucci, \& Okamoto, 2003). The existence of a functional disability, on the other hand, was established in the second phase by using the cut-off score of $\geq 5$ on the FAQ-BR (Sanchez et al., 2011), administered to the elderly's informant over the phone, in a call that lasted, on average, 7 minutes.

Each item on the FAQ has six options for responses, with points ranging from zero to three. When the informant's answer to an item points to the elderly's independence in completing an activity, it scores zero; should the informant point to a difficulty in completing the activity, it scores one; when it points to the need for help to carry out the activity, two points; and when not able to complete the activity, three points. For those activities that were not habitually completed by the elderly, the informant must specify whether the person would be able to complete them or not, if necessary. The minimum score on the FAQ is zero, and the maximum is 30 . Therefore, the lower the overall score, the higher the level of independence in completing the instrumental activities of everyday life (Pfeffer et al., 1982). The following information of the elderly was considered, collected from questions asked in personal interviews of the FIBRA-RJ baseline: gender (male or female); age (in years); education (in years of study); and MMSE results (in points). Moreover, other data from the second stage of the FIBRA-RJ was also considered: the result of the validated Brazilian version of the Informant Questionnaire on Cognitive Decline in the Elderly (IQCODE-BR; Lourenço \& Sanchez, 2014; Sanchez \& Lourenço, 2013) administered to the informant in a personal interview (in points); and, the clinical diagnosis of dementia (present or absent), based on the consensus between a neuropsychologist - who administered various cognitive and functional evaluation tests - and two geriatricians who evaluated medical history and physical, laboratory and imaging exams (MRI of the brain). The clinical diagnosis of dementia was established after two meetings of consensus following a standard protocol that considered the criteria in the Diagnostic and Statistical Manual of Mental Disorders IV (American 
Psychiatric Association [APA], 2000).

The informants of the elderly had the following information considered, from questions asked in interviews over the phone during the second stage of the FIBRA-RJ: gender (male or female); age (in years); education (in years of study); relationship to the elderly (child, spouse or other) and; common residence with the elderly (yes or no). The result of the MMSE administered during personal interviews in the second stage of the FIBRA-RJ (in points) was also considered.

In order to evaluate the accuracy of the FAQBR in screening for dementia - or the validity of its predictive criteria - the same gold standard used in the validation process of the original version of the FAQ was adopted (Pfeffer et al., 1982): clinical diagnosis of dementia.

In an effort to establish a cut-off point for the FAQ-BR, the following were analyzed: sensitivity (proportion of individuals with dementia, according to the gold standard, correctly identified as such by the FAQ-BR); specificity (proportion of individuals without dementia, according to the gold standard, correctly identified as such by the FAQ-BR); positive predictive values (ratio of true positives among all who had positive scores on the FAQ-BR); negative predictive values (ratio of true negatives among all who had negative scores on the FAQ-BR); and the positive likelihood ratio (sensitivity divided by the difference between 1 and the specificity). Intervals of 95\% confidence (IC95\%) were calculated for all these estimates.

The FAQ-BR scoring was considered continuously, and the best cut-off point was defined by Youden's Index ( () , a measurement that summarizes the evaluation of the ROC curve and enables the selection of an ideal cut-off point. This index corresponds to the highest value in the equation [sensitivity + specificity -1 ] and ranges from -1 to +1 , where the value closest to 1 indicates the adequate cut-off point. The cut-off point with the highest sensitivity and specificity on the ROC curve was also evaluated using the smallest value in the equation [ 1 sensitivity $\left.)^{2}+(1-\text { specificity })^{2}\right]$. The accuracy of the FAQ-BR (ratio of correct results, both positive and negative for dementia) was estimated using the area under the ROC curve, with an IC95\%.

The Pearson correlation coefficient $(r)$ was used to evaluate the concurrent validity of the FAQ$\mathrm{BR}$, comparing its score with those obtained by the MMSE administered to the elderly and the Informant Questionnaire on Cognitive Decline in the Elderly-Brazil (IQCODE-BR). Scoring on the MMSE ranges from zero to 30, and high overall scores indicate an absence of cognitive deficit (Brucki et al., 2003). The IQCODE-BR scores range from zero to 130 , and the final score is obtained by adding the values of all the answers to the items, divided by the total number of items. Therefore, low final scores indicate the absence of cognitive deficit (Lourenço \& Sanchez, 2014; Sanchez \& Lourenço, 2013). It is worth highlighting that the normal distribution of data was tested and confirmed, which enabled the use of the Pearson correlation coefficient.

In order to research the influence of informants' cognitive and sociodemographic characteristics on the FAQ-BR results, multivariate logistic regression analyses were made, adjusted for gender, age, education, relationship to the elderly, common residence with the elderly and MMSE results. In examining the influence of sociodemographic characteristics of the elderly on FAQ-BR results, multivariate logistic regression analyses were also carried out, but these were adjusted only for gender, age, and education. Both logistic regression analyses were based on the Wald test, adopting a significance level of $<0.05$.

The FIBRA-RJ was approved by the Ethics Research Committee at the University Hospital Pedro Ernesto at the Rio de Janeiro State University (1850/2007), by Resolution no. 466/2012 and Resolution no. 510/2016 of the National Health Council. All elderly and their informants signed an informed consent form.

\section{Results}

Females were 196 (74\%) of the elderly and $218(82.1 \%)$ of the informants. In terms of the age bracket, $117(44.2 \%)$ of the elderly were between 75 and 84 years old, and 97 $(36.6 \%)$ of the informants were 75 or older. Among participants in the study, 121 (45.7\%) of the elderly and 227 (85.7\%) of the informants had at least nine years of schooling. Of the informants, 137 (55.7\%) were children of 
the elderly, $43(17.5 \%)$ were spouses, and 162 $(61.2 \%)$ lived with them. The average score on the MMSE for the elderly was $23.3( \pm 6.3)$ and for their informants $28.3( \pm 2.1)$.

According to the gold standard, 115 (43.4\%) elderly were diagnosed with dementia. In Table 1 , we see the sensitivity and specificity for each of the cut-off points of the FAQ-BR.
Both Youden's index $(J=0.52)$, as well as the point of maximum sensitivity and specificity, give the value of $\geq 14$ as the most adequate for identifying the elderly at the greatest risk for dementia. A total of 145 (54.7\%) elderly scored $\geq 14$. The area under the ROC curve indicated the accuracy of the FAQ-BR equal to $79.7 \%$ (IC95\% 74.3 - 84.4).

Table 1

Sensitivity e specificity of cut-off points for the FAQ-BR compared to the clinical diagnosis of dementia

\begin{tabular}{lccc}
\hline Cut-off point & Sensitivity $($ IC95\%) & Specificity $($ IC95\%) & $n(\%)$ \\
\hline$\geq 6$ & $100.0(96.8-100.0)$ & $30.0(22.8-38.0)$ & $234(88.3)$ \\
$\geq 7$ & $97.39(92.6-99.5)$ & $34.67(27.1-42.9)$ & $220(83.0)$ \\
$\geq 8$ & $95.65(90.1-98.6)$ & $43.33(35.3-51.7)$ & $210(79.2)$ \\
$\geq 9$ & $93.91(87.9-97.5)$ & $48.0(39.8-56.3)$ & $195(73.6)$ \\
$\geq 10$ & $91.3(84.6-95.8)$ & $52.67(44.4-60.9)$ & $186(70.2)$ \\
$\geq 11$ & $87.83(80.4-93.2)$ & $57.33(49.0-65.4)$ & $176(66.4)$ \\
$\geq 12$ & $86.09(78.4-91.8)$ & $62.67(54.4-70.4)$ & $165(62.3)$ \\
$\geq 13$ & $83.48(75.4-89.7)$ & $67.33(59.2-74.8)$ & $155(58.5)$ \\
$\geq 14$ & $80.0(71.5-86.9)$ & $72.0(64.1-79.0)$ & $145(54.7)$ \\
$\geq 15$ & $73.91(64.9-81.7)$ & $75.33(67.6-82.0)$ & $134(50.6)$ \\
$\geq 16$ & $69.57(60.3-77.8)$ & $77.33(69.8-83.3)$ & $122(46.0)$ \\
$\geq 17$ & $67.83(58.5-76.2)$ & $79.33(72.0-85.5)$ & $114(43.0)$ \\
$\geq 18$ & $63.48(54.0-72.3)$ & $81.33(74.2-87.2)$ & $109(41.1)$ \\
$\geq 19$ & $60.0(50.4-69.0)$ & $82.67(75.6-88.4)$ & $101(38.1)$ \\
$\geq 20$ & $55.65(46.1-64.9)$ & $84.0(77.1-89.5)$ & $95(35.8)$ \\
$\geq 21$ & $49.57(40.1-59.0)$ & $86.67(80.2-91.7)$ & $88(33.2)$ \\
\hline
\end{tabular}

Note. IC95\% = Confidence Interval of $95 \%$.

The cut-off point $\geq 14$ showed sensitivity of $80.0 \%$ (IC95\% 71.5 - 86.9) and specificity of $72.0 \%$ (IC95\% 64.1 - 79.0). The positive and negative predictive values were $68.7 \%$ (IC95\%
$60.1-76.4$ ) and $82.4 \%$ (IC95\% $74.8-88.5$ ), respectively, and the positive likelihood ratio was equal to 2.86 (IC95\% 1.69 - 3.40; Table 2). 
Table 2

Diagnostic properties of the FAQ-BR with a cut-off point of $\geq 14$ compared to the clinical diagnosis of dementia

\begin{tabular}{lccc}
\hline \multirow{2}{*}{ FAQ-BR } & \multicolumn{2}{c}{ Dementia } & \multirow{2}{*}{ Total } \\
\cline { 2 - 3 } & Present & Absent & 145 \\
Positive & 96 & 49 & 120 \\
Negative & 19 & 101 & 265 \\
Total & 115 & 150 & \\
\hline
\end{tabular}

Note. FAQ-BR = Brazilian version of the Functional Activities Questionnaire; Sensitivity $=80.0 \%$ (IC95\% 71.5 86.9); Specificity $=72.0 \%$ (IC95\% 64.1 - 79.0); Negative Predictive Value $=82.4 \%$ (IC95\% $74.8-88.5)$; Positive Predictive Value = 68.7\% (IC95\% 60.1 - 76.4); Positive likelihood ratio $=2.86($ IC95\% 1.69 - 3.40).

Scoring on the FAQ-BR indicated negative correlation to the MMSE scoring $(r=-0.624 ; p<$ $0.001)$ and positive with the IQCODE-BR $(r=$ $0.755 ; p<0.001)$.
In accordance with Table 3, the results of the logistic regression indicated a statistically significant influence of only one variable in the score $\geq 14$ on the FAQ-BR: age of the elderly $(p=0.001)$.

Table 3

Results of the multivariate logistic regression on the influence of characteristics of the elderly and their informants on score $\geq 14$ on the FAQ-BR

\begin{tabular}{lccccc}
\hline Variables & $\beta$ & $\begin{array}{c}\text { Standard } \\
\text { Error }\end{array}$ & $\operatorname{Exp}(\beta)$ & $\operatorname{Exp}(\beta)-1$ & $p^{*}$ \\
\hline $\begin{array}{l}\text { Informant } \\
\quad \text { Female }\end{array}$ & 0.344 & 0.412 & 0.739 & -0.261 & 0.375 \\
$\quad$ Age & 0.023 & 0.015 & 0.978 & 0.022 & 0.122 \\
$\quad$ Education & 0.005 & 0.065 & 1.005 & 0.005 & 0.943 \\
$\quad$ Relation to the elderly & & & & & \\
$\quad$ Spouse & 0.534 & 0.390 & 0.587 & 0.413 & 0.172 \\
$\quad$ Other & 0.247 & 0.527 & 0.781 & 0.219 & 0.640 \\
$\quad$ Not residing with the elderly & 0.302 & 0.341 & 0.739 & 0.261 & 0.375 \\
$\quad$ MMSE & 0.142 & 0.089 & 0.867 & 0.133 & 0.108 \\
Elderly & & & & & \\
$\quad$ Female & 0.287 & 0.309 & 0.750 & 0.250 & 0.354 \\
Age & 0.102 & 0.019 & 0.903 & 0.097 & 0.001 \\
$\quad$ Education & 0.006 & 0.027 & 0.994 & 0.006 & 0.831 \\
\hline
\end{tabular}

Note. $\beta=$ Beta; ${ }^{*} p=$ Level of Significance (Wald Test); MMSE = Mini-Mental State Examination.

\section{Discussion}

The objective of this study was to evaluate the accuracy of the FAQ-BR in screening for dementia based on the report of the elderly's informant. Evidence presented here indicates that, with a cut-off point $\geq 14$, the ratio of correct results, sensitivity and specificity proved to be inappropriate, making the FAQ-BR not suitable as a screening test, since it failed to remove the diagnostic probability of dementia in a little over $1 / 4$ of the elderly and to correctly identify $1 / 5$ of those at risk of presenting with that illness. In light of this, it is not possible to recommend the use of FAQ-BR for screening for dementia, whether in epidemiological studies or medical practice.

Studies that have measured the performance of the FAQ in screening dementia in non-institutionalized elderly in Spain and Finland established much lower cut-off points and higher values of sensitivity and specificity than those found in this study, thus concluding that the FAQ has a validity of predictive criteria for dementia in those countries. Based on the informant's report, the 
best cut-off point established in the Spanish study (Cruz-Orduña et al., 2012) was 8/9 (sensitivity: 86.7\%; specificity: $82.1 \%$ ) and in Finland (Juva et al., 1997), > 7 (sensitivity: 94.0\%; specificity: $84.0 \%)$.

The differences between the results of this study and those of the studies cited previously may be due to the diagnostic method of dementia adopted as a gold standard by this study, completed after two meetings of consensus between a neuropsychologist - who administered various cognitive and functional evaluation tests - and two geriatricians - who evaluated clinical history, and physical, laboratory and imaging exams, considering criteria in the Diagnostic and Statistical Manual of Mental Disorders IV (APA, 2000), as detailed in a previous publication (Ribeiro, Lopes, \& Lourenço, 2013). The other studies used the evaluation of only one neurologist physician, based only on cognitive and functional tests to establish the diagnosis of dementia (Juva et al., 1997; Cruz-Orduña et al., 2012). This aspect should be highlighted since it is known that, in general, it is necessary to have more than one evaluation to establish a clinical diagnosis of dementia, since, in this way, the cognitive areas affected are thoroughly described, as well as the severity of the dysfunction, the functional damage and the etiology of dementia in order to establish the appropriate treatment (Parmera \& Nitrini, 2015).

Another aspect that helps explain the reason for the results not being in favor of the FAQ-BR's validity of predictive criteria for dementia is the fact that the concepts (constructs) of dementia and functional capacity are not equivalent, although the important interaction between the functional status of the elderly and the cognitive area is acknowledged, since a change in this dimension entails some functional impairment (Fagundes et al., 2017; Paixão Junior \& Reichenheim, 2005; WHO, 2017). Therefore, although the instruments for measuring functional ability may be used in detecting and predicting dementia in the elderly (Barberger-Gateau et al., 1999; Juva et al., 1997), in the case of the FAQ-BR, this is not applicable. Nevertheless, it is worth emphasizing that, in evaluating the dimensional structure of the FAQ-BR (Jomar et al., 2018), three items proved to be capable of capturing one of the areas of functional ability in the elderly: Memory/Cognition (Fagundes et al., 2017; Paixão Junior \& Reichenheim, 2005). Scores on the FAQ-BR showed high and statistically significant correlations with scores on the MMSE and the IQCODE-BR. The MMSE is the screening tool for cognitive decline and dementia most widely used in epidemiological studies and showed adequate diagnostic qualities in its validation study for use in Brazil (Lourenço \& Veras, 2006), as did the IQCODE-BR (Lourenço \& Sanchez, 2014; Sanchez \& Lourenço, 2013), also used to detect cognitive decline in the elderly, but based on the informant's report. In light of this, it is possible to state that the FAQ-BR, although it did not demonstrate suitable validity of predictive criteria for dementia, it did show suitable concurrent validity when compared to other tools for screening cognitive decline and/or dementia - based on the report of an informant or not-already validated and in established use in Brazil.

Encouraging results regarding the accuracy of the FAQ-BR in screening dementia were observed in the logistic regression analyses: the probability of its result being $\geq 14$ was not influenced by gender, age or education of the informant, nor by the relationship with the elderly (whether child or spouse) or whether the informant resides with the elderly or not. Regarding the characteristics of the elderly, just as in the Finnish study (Juva et al., 1997), age demonstrated influence on the probability of the FAQ-BR result suggesting dementia. Longer life has an associated risk of physiological decline in body functions and, because of this, increases the probability of chronic or debilitating diseases occurring, such as dementia, the prevalence of which increases with age, although it is not a normal aspect of aging (WHO, 2017). In FIBRA-RJ, the prevalence of dementia was 16.9 and proved to be associated with advanced age and a low level of schooling (Ribeiro et al., 2013). It is worth noting that the Finnish study concluded that there is a reduced effect of the elderly's schooling on the FAQ results, although this effect was not enough to change the established cut-off point (Juva et al., 1997). Due to the similarity in the schooling of the population included in this study, the effect reported by the Finnish study was not observed here. Thus, we recommend that future studies be done to research a possible influence of schooling, as well as the gender of the elderly, on FAQ-BR scores. This is because, although the results of the logistic regression re- 
jected the hypothesis of influence by the elderly's female gender on the score $\geq 14$ on the FAQBR $(p=0.354)$, this current sample of elderly was composed primarily of women (74\%), and it is believed that additional analyses are necessary, since, on their whole, those evaluations would complement the scrutiny of the FAQ-BR's diagnostic properties in screening dementia and the (un)suitability of its use in Brazil for this purpose. It should be mentioned that this study presents limitations, such as rejecting the participation of 57 elderly (17.7\%), who should have undergone clinical research for dementia during the second baseline phase of the FIBRA-RJ, and the average time of five months $( \pm 0,3)$ between the administration of the FAQ-BR and diagnosis of that illness. It is possible that some of the elderly persons were classified as false negatives, since the symptoms of cognitive or functional decline may have emerged during that period and, as such, only clinical research was capable of detecting dementia, underestimating the accuracy of the FAQ-BR. Another limitation to highlight is the fact that $38.8 \%$ of the informants did not live with the elderly, which may have hindered their status as qualified informants for the administration of the FAQ-BR since they might not have an evolving and detailed knowledge of the routine and status of the elderly's functional performance. One aspect that also deserves to be highlighted is about the implementation of the FAQ-BR over the phone, different from the original validation study, in which the interview was done in person (Pfeffer et al., 1982).

Despite this, the current study has positive aspects, such as the fact that the FAQ-BR was administered by a trained team of interviewers and the diagnosis of dementia was reached by consensus between two geriatricians and one neuropsychologist using the standard protocol, which considered criteria from the Diagnostic and Statistical Manual of Mental Disorders IV (APA, 2000).

\section{Conclusion}

Although the results of this study refer to a specific population and, therefore, impose limits on generalizations, these contribute to the process of transcultural adaptation of the FAQ for use in Brazil, by bringing out diagnostic properties that, for now, do not allow for the recommendation of its administration in epidemiological studies for screening dementia, based on reports by informants of the elderly.

\section{References}

American Psychiatric Association. (2000). Diagnostic and statistical manual of mental disorders: DSM-IV-TR. Washington, WA: Author.

Barberger-Gateau P., Fabrigoule C., Helmer C., Rouch I., \& Dartigues, J. F. (1999). Functional impairment in instrumental activities of daily living: An early clinical sign of dementia? Journal of the American Geriatrics Society, 47(4), 456-462. doi: 10.1111/j.15325415.1999.tb07239.x

Brucki, S. M., Nitrini, R., Caramelli, P., Bertolucci, P. H., \& Okamoto, I. H. (2003). Sugestóes para o uso do mini-exame do estado mental no Brasil. Arquivos de Neuro-Psiquiatria, 61(3), 777-81. doi:10.1590/ S0004-282X2003000500014

Cruz-Orduña, I., Bellón, J. M., Torrero, P., Aparicio, E., Sanz, A., Mula, N., ... Olazarán, J. (2012). Detecting $\mathrm{MCI}$ and dementia in primary care: Effectiveness of the MMS, the FAQ and the IQCODE. Family Practice, 29(4), 401-406. doi: 10.1093/fampra/cmr114

Fagundes, T. A., Pereira, D. A., Bueno, K. M., \& Assis, M. G. (2017). Functional disability in elderly with dementia. Cadernos Brasileiros de Terapia Ocupacional, 25(1),159-169. doi:10.4322/0104-4931.ctoAO0818

Hendry, K., Quinn, T. J., Evans, J. J., \& Stott, D. J. (2015). Informant single screening questions for delirium and dementia in acute care: A cross-sectional test accuracy pilot study. BMC Geriatrics, 15, 17. doi:10.1186/s12877-015-0016-1

Jomar, R. T., Lourenço, R. A., \& Lopes, C. S. (2017). Construct validity of the Brazilian version of the Functional Activities Questionnaire. Geriatrics, Gerontology and Aging, 11(4), 170-173. doi:10.5327/ Z2447-211520171700064

Jomar, R.T., Lourenço, R. A., \& Lopes, C. S. (2018). Estrutura dimensional da versão brasileira do Functional Activities Questionnaire (FAQ-BR). Cadernos de Saúde Pública, 34(11), e00209917. doi:10.1590/ 0102-311x00209917

Juva, K., Makela, M., Erkinjunti, T., Sulkava, R., Ylikoski, R., Valvanne, J., \& Tilvis R. (1997). Functional assessment scales in detecting dementia. Age and Ageing, 26(5), 393-400. Retrieved from https://pdfs.semanticscholar.org/5408/be2126aae9f6692d92664eaa261fe23f362d.pdf

Lourenço, R. A., Sanchez, M. A., Moreira, V. G., Ribeiro, 
P.C., Perez M., Campos G. C., ... Teldeschi, A. L. (2015). Fragilidade em Idosos Brasileiros - FIBRA-RJ: Metodologia de pesquisa dos estudos de fragilidade, distúrbios cognitivos e sarcopenia. Revista HUPE, 14(4), 13-23. doi:10.12957/rhupe.2015.20066

Lourenço, R. A., \& Sanchez, M. A. (2014). Accuracy of the Brazilian version of the Informant Questionnaire on Cognitive Decline in the Elderly at screening for dementia in community-dwelling elderly participants: findings from FIBRA-RJ Study. Journal of Geriatric Psychiatry and Neurology, 27(3), 212-219. doi:10.1177/0891988714524626

Lourenço, R. A., \& Veras, R. P. (2006). Mini-Mental State Examination: Psychometric characteristics in elderly outpatients. Revista de Saúde Pública, 40(4), 712-719. doi: 10.1590/S0034-89102006000500023

Paixão Junior, C. M., \& Reichenheim, M. E. (2005). Uma revisão sobre instrumentos de avaliação do estado funcional do idoso. Cadernos de Saúde Pública, 21(1), 7-19. doi:10.1590/S0102-311X2005000100002

Parmera, J. B., \& Nitrini, R. (2015). Demências: Da investigação ao diagnóstico. Revista de Medicina, 94(3), 179-184. doi:10.11606/issn.1679-9836. v94i3p179-184

Pfeffer, R. I., Kurosaki, T. T., Harrah Jr., C. H., Chance, J. M., \& Filos, S. (1982). Measurement of functional activities in older adults in the community. Journal of Gerontology, 37(3), 323-329. Retrieved from https://academic.oup.com/geronj/article-ab- stract/37/3/323/611005? redirectedFrom=PDF

Ribeiro, P. C., Lopes, C. S., \& Lourenço, R. A. (2013). Prevalence of dementia in elderly clients of a private health care plan: A study of the FIBRA-RJ, Brazil. Dementia and Geriatric Cognitive Disorders, 35(1-2), 77-86. doi:10.1159/000345984

Sanchez, M. A., Correa, P.C., \& Lourenço, R. A. (2011). Cross-cultural adaptation of the "Functional Activities Questionnaire - FAQ" for use in Brazil. Dementia \& Neuropsychologia, 5(4), 322-327. doi:10.1590/ S1980-57642011DN05040010

Sanchez, M. A., \& Lourenço, R. A. (2013). Screening for dementia: Brazilian version of the Informant Questionnaire on Cognitive Decline on the Elderly and its psychometric properties. Geriatrics \& Gerontology International, 13(3), 687-693. doi:10.1111/j. 1447-0594.2012.00966.x

Sposito, G., Neri, A. L., \& Yassuda, M. S. (2016). Advanced activities of daily living (AADLs) and cognitive performance in community-dwelling elderly persons: Data from the FIBRA Study - UNICAMP. Revista Brasileira de Geriatria e Gerontologia, 19(1), 7-20. doi:10.1590/1809-9823.2016.15044

World Health Organization. (2017). Global action plan on the public health response to dementia 2017-2025. Retrieved from https://apps.who.int/iris/bitstream/ handle/10665/259615/9789241513487-eng.pdf;jsessionid=BE9F2F0AFA076A56C11D8B92415B6D$9 \mathrm{~F}$ ? sequence $=1$ 
